\title{
LABORATORY EVALUATION OF BORIC ACID SUGAR BAITS AGAINST IRRADIATED AEDES AEGYPTI
}

\author{
VINDHYA S. ARYAPREMA', KAI BLORE', JEDIDIAH KLINE2, \\ ROBERT L. ALDRIDGE2, KENNETH J. LINTHICUM ${ }^{2}$, AND RUI-DE XUE' \\ 'Anastasia Mosquito Control District, 120, EOC Drive, \\ St. Augustine, Florida, USA \\ USDA-Center for Medical, Agricultural \& Veterinary Entomology, \\ Gainesville, Florida, USA
}

Subject Editor: Eva Buckner

\begin{abstract}
The use of attractive toxic sugar baits (ATSBs) is a new paradigm in mosquito control. ATSBs kill both female and male mosquitoes attracted to sugar feed on a sugary solution containing a toxic substance such as boric acid. The impact of boric acid sugar baits on irradiated and non-irradiated Aedes aegypti was evaluated in the laboratory to determine any difference in mortality between the two groups. The mortality rates from the toxic sugar baits in both irradiated with $50 \mathrm{~Gy}$ and non-irradiated groups were highly significantly different, compared to those of corresponding control groups $(\mathrm{t}=6.916, \mathrm{p}<0.0001$ and $\mathrm{t}=6.451, \mathrm{p}<0.01$, respectively). Irradiated Ae. aegypti were not significantly different in mortality rates from non-irradiated counter parts after 24 and 48 h exposure to toxic sugar bait $(\mathrm{t}=0.576, \mathrm{p}=0.578$ and $\mathrm{t}=0.642, \mathrm{p}=0.535$ respectively). There was no significant difference in mortality caused by toxic sugar baits between the two sexes $(t=0.595, p=0.869$ and $t=0.169, p=0.869$ for irradiated and non-irradiated groups, respectively). The mean percent mortality after $48 \mathrm{~h}$ of exposure to toxic sugar baits was $43.3 \%$ for irradiated mosquitoes and $38.6 \%$ for non-irradiated mosquitoes. Mortality rates were significantly higher during second $24 \mathrm{~h}$ period in both irradiated and non-irradiated groups $(\mathrm{t}=-6.612, \mathrm{p}<0.01$ and $\mathrm{t}=-5.278$, $\mathrm{p}<0.01$ respectively). The study suggests that the toxic sugar bait approach could not be used within a sterile insect technique program to reduce the wild male population to increase the chances of wild females mating with irradiated males.
\end{abstract}

Key Words: radiation, sterile insect technique, Aedes aegypti, boric acid sugar bait, mortality

Aedes aegypti Linn. is an important mosquito vector species which transmits arboviruses causing diseases, such as yellow fever, dengue, chikungunya and Zika viruses in humans (Beaumier et al. 2014, Chippaux \& Chippaux 2018, Guerbois et al. 2015, Honório et al. 2018). Vector control consists primarily of the removal of immature development habitats augmented by targeted adulticide application. Ubiquitous and cryptic breeding sites combined with the domiciliary resting behavior of the species have made density reduction challenging. Moreover, rapid evolution of insecticide resistance in Ae. aegypti populations has become a major problem. This justifies the development of novel and enhanced control strategies (Deming et al. 2016) that are environmentally friendly, sustainable, and cost-effective (WHO 2012). Sterile insect technique (SIT) is one such control strategy that has been of increasing interest (Alphey et al. 2010, Chung et al. 2018, https://www.iaea. org/topics/sterile-insect-technique ). Sterile insect technique involves the mass-rearing of mosquitoes and, release of sterile males.

Attractive-toxic sugar baits (ATSBs) that kill both female and male mosquitoes are also considered to be a promising strategy, which can be added in integrated vector management (IVM) programs for mosquito control (Fiorenzano et al. 2017). Boric acid has shown to be an effective active ingredient for the ATSB (Xue \& Barnard 2003, Bhami \& Das 2015 behind Xue \& Barnard 2002). Boric acid sugar baits applied as a foliar or surface space spray have previously demonstrated effective control of several mosquito species in field trials (Beier et al. 2012, 
Fiorenzano et al. 2017, Maia et al. 2018, Qualls et al. 2012, Qualls et al. 2015, Xue et al. 2006, 2011). However, SIT and ATSB control methods work in different ways. The SIT slowly reduces the fecundity of the wild population (Alphey et al. 2010) while the application of ATSB produces quick mortality of both males and females of targeted vector populations (Xue et al. 2006). Additionally, although SIT is species-specific, the ATSB impacts a wide range of target and non-target organisms alike given the generic effect of some active ingredients.

The purpose of this study was to determine if ATSB could be used to reduce the wild male population within a SIT program to increase the chances of wild females mating with irradiated males. The impact of ATSB on adult female Ae. aegypti was also evaluated, because it is possible for some irradiated females to also be released with the sterile males. A laboratory experiment was conducted with colonized Ae. aegypti (St. Augustine strain 2016) provided by the USDA-Center for Medical, Agricultural \& Veterinary Entomology, Gainesville, Florida. Male and female Ae. aegypti pupae were irradiated with 50 Gray (Gy) by $\gamma$-radiation using a Gammator M (Radiation Machinery Corp., Parsippany, NJ) containing a cesium-137 source that generated $8.8 \mathrm{~Gy} / \mathrm{min}$. The radiation doses applied to the pupae were 0 and $50 \mathrm{~Gy}$, with the 0 Gy acting as a control. Radiation doses were checked with alanine films applied to petri dishes with pupae for every dose. Two hundred 5-7- day-old irradiated and non-irradiated males and females were mouth-aspirated into each of several separate cages $(29 \mathrm{~cm}$ L x $29 \mathrm{~cm} \mathrm{~W} \mathrm{X} 29 \mathrm{~cm} \mathrm{H}$,). The experiment was carried out with one treatment group and one control group, each with cages of irradiated males, irradiated females, non-irradiated males and non-irradiated females.

Each treatment cage was provided with a cup of cotton wool swabs (Cloud Marketing Inc. Rancho Cucamonga, CA) saturated with $5 \%$ sugar solution $+1 \%$ boric acid (Sigma-Aldrich, Co. USA) while the control cages were provided only with $5 \%$ sugar solution. Dead mosquitoes in cages were hand-picked and counted 24 and 48 $\mathrm{h}$ after the exposure to the sugar solutions (control and treatment). The remaining live mosquitoes were counted after $48 \mathrm{~h}$ to enumerate the total number in each cage and the percent mortalities were calculated based on the totals summed across two collection days. Three replicates of the experiment were carried out in three different times. Each replicate was at least one week apart to minimize any environmental bias.

Data analysis was done using SPSS $\left(\right.$ IBM ${ }^{\circledR}$ SPSS ${ }^{\circledR}$ statistics, version 20$)$. Normal distributions of the data sets were confirmed using the Shapiro-Wilk normality test. Means of percent mortalities between different groups after $48 \mathrm{~h}$ and at two $24 \mathrm{~h}$ periods were compared appropriately using independent sample t-test. The level of significance was maintained at $\mathrm{p}<0.05$.

Both irradiated and non-irradiated $A e$. aegypti had statistically significant differences in mortality rates after exposure to boric acid sugar bait (treatment) for $48 \mathrm{~h} \mathrm{com-}$ pared to the corresponding control group $(\mathrm{t}=6.916, \mathrm{p}<0.0001$ and $\mathrm{t}=6.451, \mathrm{p}<0.01$ respectively). The difference in mortality rates between irradiated and non-irradiated mosquitoes exposed to boric acid sugar bait was not significantly different at both $24(\mathrm{t}=0.576, \mathrm{p}=0.578)$ and $48 \mathrm{~h}(\mathrm{t}=0.642$, $\mathrm{p}=0.535)$ exposure periods (Figure 1). Further, no difference in mortality rates between the two sexes was documented $(\mathrm{t}=0.477, \mathrm{p}>0.05$ and $\mathrm{t}=0.511, \mathrm{p}>0.05$ for irradiated and non-irradiated groups, respectively). Mean percent mortalities after 24 and $48 \mathrm{~h}$ of boric acid sugar bait exposure were $5.89 \pm 1.30(\mathrm{SE})$ and $37.01 \pm 4.52$ (SE) respectively for irradiated mosquitoes and $4.76 \pm 1.45(\mathrm{SE})$ and $33.87 \pm 5.32(\mathrm{SE})$ respectively for non-irradiated mosquitoes. There were highly significant differences in mortality rates between the two time periods with a higher mortality after the second $24 \mathrm{~h}$ period $(\mathrm{t}=-6.612, \mathrm{p}<0.01$ for irradiated mosquitoes and $\mathrm{t}=-5.278, \mathrm{p}<0.01 \mathrm{p}<0.01$ for non-irradiated mosquitoes (Table 1 ).

The results indicate that irradiated $A e$. aegypti were as susceptible as non-irradiated Ae. aegypti when exposed to boric acid sugar 


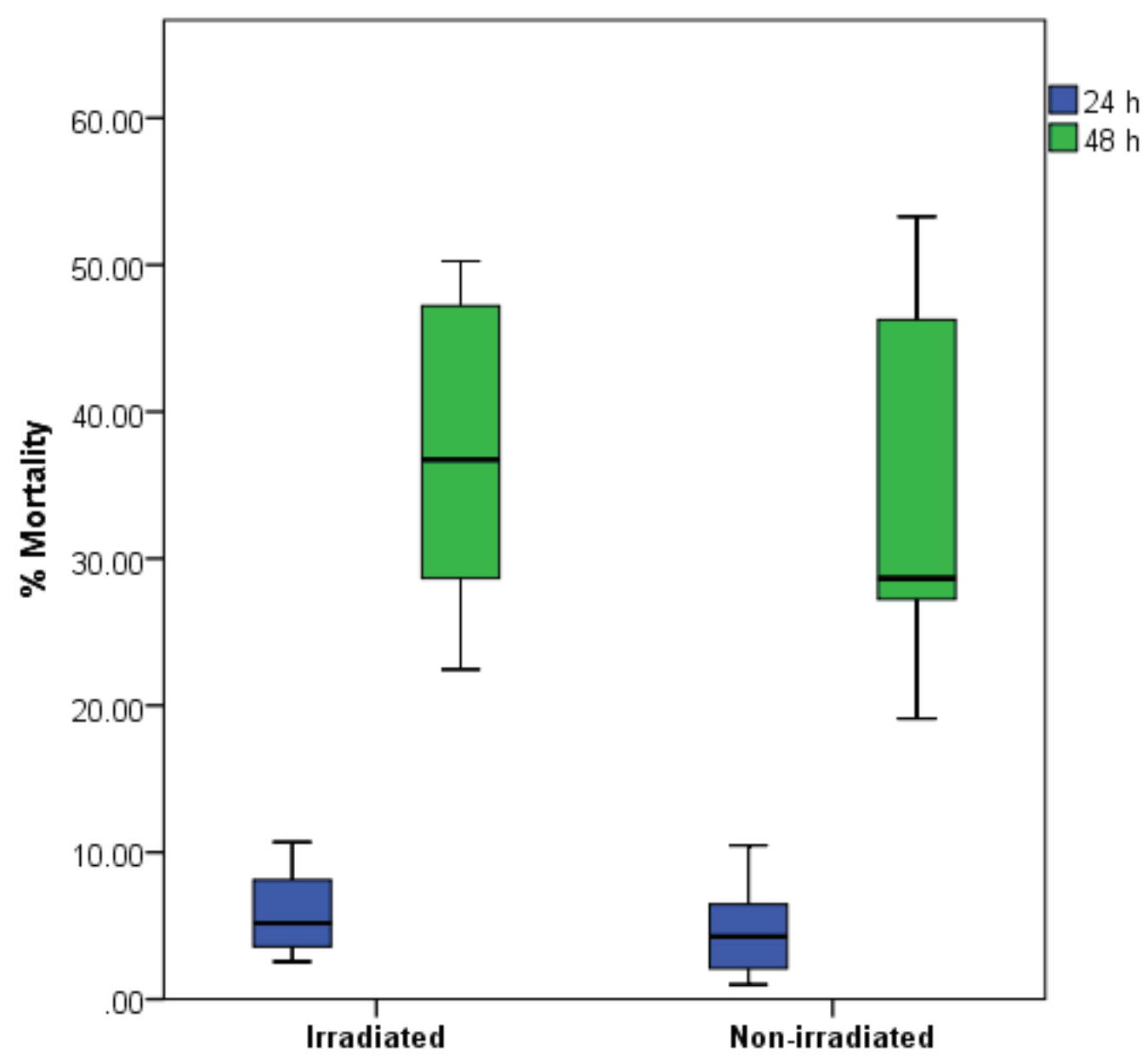

Figure 1. Mean (+ SE) mortality (\%) of irradiated and non-irradiated adult Ae. aegypti after exposure to boric acid sugar baits at $24 \mathrm{~h}$ and $48 \mathrm{~h}$ in the laboratory.

baits, and there was no statistical difference in susceptibility between males and females independent of irradiation. The results also suggest that significant mortality from boric acid sugar baits could be achieved $48 \mathrm{~h}$ post exposure. However, for the release of irradiated Ae. aegypti to be successful in controlling population densities, the released mosquitoes must disperse rapidly among the wild population so that they have a higher probability of mating with wild females within their life span (White et al. 2010). A requirement of SIT is that the release ratio is sufficiently large to overcome the natural rate of population increase, so that the trend in population size is downward following the first release (Dunn \& Follett, 2017).
Therefore, the application of boric acid sugar baits or ATSB and the release of irradiated male Ae. aegypti in the same area at the same time would not be complementary. Incorporation of the two techniques into an integrated vector management program will require considerable thought and planning to implement them both effectively. Further studies with field released irradiated and wild are suggested as the findings with colonized mosquitoes are not always indicative of what will be found with field mosquitoes.

We would like to acknowledge the support of Daniel A. Hahn and Chao Chen, University of Florida, Gainesville Florida, for supporting the research by exposing the mosquitoes in their radiator. 
Table 1. Comparison of mean $( \pm \mathrm{SE}$ ) percent mortality between irradiated and non-irradiated adult Ae. aegyptiafter exposure to boric acid sugar baits for 24 and $48 \mathrm{~h}$

\begin{tabular}{lrrr}
\hline \hline & & Mean $\pm \mathrm{SE}$ & \\
\cline { 2 - 4 } & First $24 \mathrm{~h}$ & Second $24 \mathrm{~h}$ & After $48 \mathrm{~h}$ \\
\hline Irradiated-treated & $5.89 \pm 1.30$ & $37.01 \pm 4.52$ & $43.32 \pm 4.68$ \\
Irradiated-control & $1.11 \pm 0.45$ & $1.20 \pm 0.18$ & $2.31 \pm 0.57$ \\
Non-irradiated-treated & $4.76 \pm 1.45$ & $33.87 \pm 5.32$ & $38.61 \pm 5.63$ \\
Non-irradiated-control & $1.36 \pm 0.51$ & $0.26 \pm 0.18$ & $1.63 \pm 0.63$ \\
\hline
\end{tabular}

\section{REFERENCES CITED}

Alphey L, Benedict M, Bellini R, Clark GG, Dame DA, Service MW, Dobson SL. 2010. Sterile-Insect Methods for Control of Mosquito-Borne Diseases: An Analysis. Vector Borne Zoonotic Dis. 10: 295-311.

Beaumier C, Melissa N. Garcia MN, KMurray KO. 2014. The History of Dengue in the United States and its Recent Emergence. Current Tropical Medicine Reports. 1: 32-35.

Beier JC, Müller GC, Gu W, Arheart KL, Schlein Y. 2012. Attractive toxic sugar bait (ATSB) methods decimate populations of Anopheles malaria vectors in arid environments regardless of the local availability of favored sugar-source blossoms. Malar J. 11:31.

Bhami LC, Das SS. 2015. Boric acid ovicidal trap for the management of Aedes species. J Vector Borne Dis. 52:147-52.

Chippaux, J., Chippaux, A. Yellow fever in Africa and the Americas: a historical and epidemiological perspective. J Venom Anim Toxins Incl Trop Dis 24, 20 (2018). https://doi.org/10.1186/s40409-018-0162-y

Chung HN, Rodriguez SD, Gonzales KK, Vulcan J, Cordova JJ, Mitra S, Adams CG, Moses-Gonzales N, Tam N,Cluck JW, Attardo GM, Hansen IA. 2018. Toward implementation of mosquito sterile insect technique: The effect of storage conditions on survival of male Aedes aegypti mosquitoes (Diptera: $\mathrm{Cu}-$ licidae) during transport. J Insect Sci. 18(6) 2. doi. org/10.1093/jisesa/iey103.

Deming R, Manrique-Saide P, Medina Barreiro A, Cardeña EU, Che-Mendoza A, Jones B, Liebman K, Vizcaino L, Vazquez-Prokopec G, Lenhart A. 2016. Spatial variation of insecticide resistance in the dengue vector Aedes aegypti presents unique vector control challenges. Parasit. Vectors 9: 67.

Dunn DW, Follett PA. 2017. The Sterile Insect Technique (SIT) - an introduction. doi.org/10.1111/ eea.12619.

Fiorenzano JM, Koehler PG, Xue RD. 2017. Attractive Toxic Sugar Bait (ATSB) For Control of Mosquitoes and Its Impact on Non-Target Organisms: A Review. Int JEnviron Res Public Health. 14: 398. doi: 10.3390/ ijerph 14040398
Guerbois M, Fernandez-Salas I, Azar SR, Danis-Lozano R, Alpuche-Aranda CM, Leal G, Garcia-Malo IR, Diaz-Gonzalez EE, Casas-Martinez M, Rossi SL. Et al. 2016. Outbreak of Zika Virus Infection, Chiapas State, Mexico, 2015, and First Confirmed Transmission by Aedes aegypti Mosquitoes in the Americas. The Journal of Infectious Diseases, Volume 214, Issue 9, 1 November 2016, Pages 1349-1356, https://doi. org/10.1093/infdis/jiw302

Honório NA, Wiggins K, Câmara DCP, Eastmond B, Alto BW. 2018. Chikungunya virus vector competency of Brazilian and Florida mosquito vectors. PLoS Negl Trop Dis. 2018 Jun; 12(6): doi: 10.1371/journal. pntd.0006521.

Maia MF, Tenywa FC, Hannah Nelson H, Kambagha A, Ashura A, Bakari I, Mruah D, Simba A, Bedford A. 2018. Attractive toxic sugar baits for controlling mosquitoes: a qualitative study in Bagamoyo, Tanzania. Malaria Journal. 17:22.

Qualls WA, Xue RD, Revay EE, Allan SA, Müller GC. 2012. Implications for operational control of adult mosquito production in cisterns and wells in St. Augustine, FL using attractive sugar baits. Acta Trop. 124:158-61.

Qualls WA, Müller GC, Traore SF, Traore MM, Arheart KL, Doumbia S, Schlein Y, Kravchenko VD, Xue RD, Beier JC. 2015. Indoor use of attractive toxic sugar bait (ATSB) to effectively control malaria vectors in Mali, West Africa. Malaria Journal, 14:301.

White SM, Rohani P, Sait SM. 2010. Modelling pulsed releases for sterile insect techniques: fitness costs of sterile and transgenic males and the effects on mosquito dynamics. J Appl. Ecol. 47: 1329-1339.

WHO. 2012. Global Plan for Insecticide Resistance Management in Malaria Vectors. World Health Organization; Geneva, Switzerland).

Xue RD, Barnard DR. 2003. Boric acid bait kills adult mosquitoes. JEcon Entomol 96:1559-1562.

Xue RD, Kline DL, Ali A, Barnard DR. 2006. Application of boric acid baits to plant foliage for adult mosquito control. J Am Mosq Control Assoc. 22:497-500.

Xue RD, Müller GC, Kline DL, Barnard DR. 2011. Effect of application rate and persistence of boric acid sugar baits applied to plants for control of Aedes albopictus. JAm Mosq Control Assoc. 27:56-60. 